\title{
MORRENDO BEM EQUIPADO
}

\author{
A WELL-EQUIPPED PASSING AWAY
}

Anísio Baldessin

Padre da Ordem de São Camilo. Capelão no Hospital das Clínicas de São Paulo da Faculdade de Medicina - USP. anisio.baldessin@bol.com.br

Baldessin A. (Padre). Morrendo bem equipado. Medicina (Ribeirão Preto) 2005; 38 (1): 55-59.

Resumo: A morte, principalmente na cultura ocidental, sempre foi encarada com muita resistência. Essa realidade pode ser comprovada no cotidiano onde as crianças são, cada vez mais, afastadas do convívio com a morte. Para fugir desta realidade, a medicina, com o auxílio da alta tecnologia, busca alternativas para afastar o "fantasma" da morte.

A proposta deste artigo é refletir sobre o uso da tecnologia que, ao mesmo em que tempo prolonga a vida, acarreta sofrimentos ao paciente, familiares, profissionais e àqueles que devem arcar com os custos da hospitalização. Neste sentido, o autor do artigo chama atenção dos leitores para o seguinte fato: enquanto se gasta muito tempo e dinheiro tentando evitar a morte física, pouco ou quase nada se faz para evitar os outros tipos de morte que muitas vezes, são piores do que a morte física.

Descritores: Morte. Ortotanásia.

A morte, principalmente na civilização ocidental, sempre foi encarada com muita resistência. Apesar de ser ela uma realidade em nossa vida, estamos sempre tentando fugir. Para isso usamos os avanços tecnológicos para, a qualquer preço, prolongá-la. Pois ainda que a continuidade da vida, quando marcada por terríveis sofrimentos seja difícil, para o doente, familiares e profissionais e até onerosa para a sociedade, lutamos desesperadamente para, pelo menos, manter a pessoa viva.

Em seu livro, A tirania da sobrevivência, o bioeticista Daniel Callahan ${ }^{1}$, afirma que, "nenhum outro progresso tem sido tão espetacular na medicina como o domínio de sofisticadas tecnologias diagnósticas e terapêuticas".

Baseada nesta teoria, a educação dos médicos hoje, é orientada para o uso dessas tecnologias. A indústria as produz e os sistemas de saúde preocupam-se em utilizá-las e pagá-las. O sucesso médico dessas tecnologias é, em muitos casos, um verdadeiro milagre, fonte de orgulho profissional e de admiração pública. E para muitas pessoas, a disponibilidade de toda essa tecnologia para consertar as marcas do "destino" é uma fonte de esperança, consolo e vida longa.

Por outro lado, tais tecnologias aumentaram demasiadamente o custo da medicina e dos tratamentos de saúde. Elas provêm tratamento onde previamente não existia, e torna possível novas formas de reabilitação e extensão da vida. E a tendência natural é avançar para tratamentos sempre mais sofisticados e custosos.

\section{O BEM OU OS BENS DO DOENTE?}

Segundo a revista inglesa Focus, embora não tenham a popularidade da Microsoft ou McDonald's, os laboratórios farmacêuticos são os negócios mais lucrativos do planeta, perdendo apenas para as com- 
panhias de petróleo. Pois, no ano passado, o setor teria faturado 406 bilhões de dólares ${ }^{2}$. No entanto, enquanto os laboratórios estão cada vez mais saudáveis do ponto de vista financeiro, a imensa maioria dos habitantes do mundo permanece doente.

Outro dado alarmante é que mais de $80 \%$ dos resultados dos exames dão resultados negativos. Em princípio, esse dado pode parecer positivo. No entanto, isso leva crer que muitos exames de alto custo poderiam ser evitados, se houvesse uma boa relação (conversa) entre profissionais e pacientes.

Não podemos esquecer também os aparelhos de última geração que são usados nas unidades de terapia intensiva. Aparelhos que trazem lucros exorbitantes aos fabricantes, desgaste para quem faz uso deles, hospital e/ou familiares do paciente, angústia e sofrimento para o paciente que muitas vezes, tem prolongado, não a sua vida, mas sim seu processo do morrer. Fato que acontece com muita frequiência.

É o eterno drama dos profissionais, familiares e principalmente do paciente que é o mais interessado, mas que na maioria das vezes não têm o direito de opinar.

\section{E O PRINCÍPIO DA AUTONOMIA?}

A definição deste princípio é muito bonita. Vejamos: "Autonomia - autos, eu; nomos, lei. Diz respeito à capacidade que tem a racionalidade humana de fazer leis para si mesma. Significa a capacidade de a pessoa governar-se a si mesma, ou a capacidade de se autogovernar, escolher, dividir, avaliar, sem restrições internas ou externas. Ou seja, os pacientes não são objetos e sim sujeitos autônomos que estabelecem relações interpessoais, compartilham decisões em parceria e no gozo de plenos direitos".

Realmente, ao contrário do que muitas vezes, na minha ignorância afirmei não existir, descobri que este princípio, realmente existe. No entanto, trabalhando num grande hospital e de alta tecnologia, eu, guardadas as raríssimas exceções, não consegui vê-lo ser respeitado e muito menos posto em prática.

\section{TECNOLOGIA OU CONDIÇÕES DE VIDA?}

Sem cair na ignorância de negar os benefícios trazidos pela alta tecnologia, indico dois pontos para reflexão. O primeiro é que enquanto se investe milhões e milhões de reais em alta tecnologia e medica- mentos, investe-se muito pouco na melhoria das condições de vida da população. Como alguém já disse parece que mais do que estarem preocupados com o bem estar dos doentes estão buscando os bens dos doentes. Pois enganam-se aqueles que pensam que o que prolonga a vida são somente os equipamentos e medicamentos de alto custo. Pois, são poucas as pessoas que dispõem desses recursos para ter acesso a toda essa tecnologia e aos medicamentos de alto custo.

O segundo ponto parte de uma constatação feita pelo o saudoso professor Carlos da Silva Lacaz, num velório de um amigo que, mesmo cercado pelos melhores profissionais e recursos terapêuticos morreu. Assim se expressou o insigne professor: "padre, mesmo nos melhores hospitais as pessoas morrem. A única diferença é que, nestes hospitais sofisticados, os pacientes morrem bem equipados e muitas vezes mal informados".

\section{MORRENDO MAL INFORMADOS}

Realmente, embora estejamos vivendo na era da informática, da comunicação, da humanização, a informação, principalmente nos hospitais, é um grande desafio. As consultas são cada vez mais rápidas e com termos cada vez mais técnicos. As receitas médicas, na maioria das vezes são quase ilegíveis. As decisões, geralmente, são tomadas pela equipe médica e comunicada à família. Quase nunca ao paciente.

Ao paciente é oferecido quartos e hospedagem comparados aos hotéis de luxo, exames, cirurgias e aparelhos de última geração. No entanto, consciente ou inconscientemente, nega-se na prática, o princípio tão bonito de autonomia que é definido na teoria. Negase a vontade do paciente afirmando que o mesmo não tem condições, físicas, mentais para decidir. Por fim ignora-se um dos direitos que muitos reclamam que é o direito de morrer com dignidade e sem sofrimento. Por fim, nega-se a realidade da morte que é tão certa em nossas vidas.

O segredo que na realidade pertence ao paciente, o mais interessado, acaba sendo guardado pelos profissionais. Até a assistência religiosa, as vezes, lhe é negada devido a falta de representantes religiosos, empecilhos dos hospitais ou bloqueio da família que pensa que a presença de um representante religioso pode assustar o doente, apressar ou aumentar ainda mais o drama da morte. 


\section{O DRAMA DA MORTE}

Diante do trauma da morte a conduta humana reagiu socialmente com os ritos do luto, que não pretendem remover a morte, mas antes realizar uma aceitação realista e promover a superação do choque, buscando o sentido da vida que continua e da morte que aconteceu (Episcopado Alemão, 1995; Dobzhansky T., 1969) ${ }^{3}$.

Para quem busca na filosofia maneiras de lidar melhor com a morte, as reflexões finais do filósofo grego Sócrates representam um excelente exercício de aceitação: "porque morrer é uma ou outra destas duas coisas. Ou o morto não tem absolutamente nenhuma existência, nenhuma consciência do que quer que seja. Ou, como se diz, a morte é precisamente uma mudança de existência e, para a alma, uma migração deste lugar para o outro". Ou seja, para quem não acredita na continuação da vida, a morte é o nada, é a ausência completa de angústias e desesperos, é o fim das aflições. E para quem acredita na continuação da vida, a morte é a passagem desta existência para outra melhor. De qualquer maneira a dor estaria na vida e não na morte. Assim disse Sócrates antes de beber o veneno: "Mas já é hora de irmos: eu para a morte e vocês para a viverem. Mas quem vai para melhor sorte é segredo, exceto para Deus".

\section{A ORTOTANÁSIA COMO CAMINHO}

A medicina evoluiu tanto, que tornou o processo do morrer muito difícil. Como é difícil morrer hoje! Difícil e demorado! Essa realidade é tão gritante que estamos sempre falando do tema "morte" e principalmente de "eutanásia", palavra que etimologicamente (do grego "eu", boa, e "thanatos", morte) significa morte boa. Hoje ganha importância outro termo, seu antônimo: a distanásia. Segundo o dicionário Aurélio: "Med. Morte lenta, ansiosa e com muito sofrimento". Ou seja, um procedimento no qual os profissionais da saúde, tentando salvar a vida acaba gerando sofrimento. Entendendo que a morte é uma necessidade decorrente da natureza, não deveríamos ter coragem de aceitá-la ao invés de lutar contra ela, e tentar desfazer a mentalidade de anti-morte que está impregnada em nossa cultura? Daí, a necessidade de abordarmos um novo termo, a ortotanásia.

A ortotanásia procura respeitar o bem-estar global das pessoas e abre pistas para que possam garantir a dignidade no seu viver bem como no seu morrer.
Para isso, é necessário mudanças que possam ser evitados os excessos da eutanásia e da distanásia.

Assim sendo, a ortotanásia permitiria ao doente que já entrou na fase final, e aos que o cercam, enfrentar a morte com certa tranquilidade porque, nesta perspectiva, a morte não é uma doença a curar, mas sim algo que faz parte da vida. Uma vez aceito este ato, com o qual a cultura ocidental moderna tende a esconder e negar, abra-se a possibilidade de trabalhar com as pessoas a distinção entre curar e cuidar, entre manter a vida quando este é o procedimento correto e permitir que a pessoa morra quando sua hora chegou.

Neste processo, o componente ético é tão importante quanto o componente técnico. Diante disso, o grande desafio é integrar conhecimento científico, competência técnica e sensibilidade humana e ética numa abordagem multi e transdisciplinar. Quando se entende que a ciência, a técnica e a economia têm sua razão estando a serviço da pessoa humana, a partir do nível pessoal, comunitário e até sectário, descobre-se o valor do doente crônico e terminal, que facilmente pode ser marginalizado, por ser visto como uma mera despesa e exigência de cuidado.

Portanto, se nos dedicarmos ao processo de cuidar com a mesma dedicação que trabalhamos na tentativa de curar, brevemente estaremos fazendo com que as pessoas, que já entraram no processo do morrer encontrem algum sentido para viverem os dias que faltam para gozarem a outra vida.

\section{A MORTE GERA VIDA}

Se humanamente é impossível vencer a morte, algo pode amenizar nossa tristeza. Na visão humana, como está escrito no livro da Sabedoria (Cf.Sb. 3,2) a morte é uma desgraça. Numa visão biológica, querer vencer a morte é uma atitude antibiológica, pois se não morrêssemos teríamos que limitar os nascimentos. Isto porque sem espaço a humanidade deixaria de se enriquecer biologica e culturalmente. Quantas pessoas nascem com novos ideais e novas descobertas que contribuem para a própria vida? E quantas pessoas que, em determinada idade, já cansaram de viver e esperam o momento da morte? Como disse Harold Kusnher4: "o gosto pelo viver acabaria trazendo um desgosto por não poder morrer".

A morte não termina com tudo, nem destrói a vida. A vida continua, de uma maneira ou de outra. Para nós, cristãos, a promessa da ressurreição gera- 
dora da vida eterna, e somente passível de crença através da fé, ameniza nosso sofrimento. O próprio Cristo não se preocupou somente com esta vida terrena: " $O$ meu reino não é deste mundo, embora eu esteja neste mundo" (Cf Jo 18,36). É verdade porém, que muitas vezes, nem a imortalidade consola, pois a morte do outro que goza da vida eterna, traz, além de muita tristeza, alguns aborrecimentos.

\section{PIOR, NÃO É A MORTE FÍSICA}

A morte física quase sempre traz conseqüências e perdas irreparáveis. Exemplo disso é a perda do chefe de família, que dele dependia todo o sustento da família, ou a morte do presidente de uma grande empresa que, naquele momento, era considerado insubstituível embora exista o dito popular que diz "ninguém é insubstituível, e ainda que os cemitérios estão cheios de insubstituíveis".

Mas, embora seja difícil muitas vezes, essa morte, não é a pior. Pois sabemos que, mais dia menos dia, vamos morrer. Até a Bíblia fala do "benefício" da morte. "Em verdade, em verdade vos digo: se o grão de trigo, caindo na terra, não morrer fica ele só; mas, se morrer, produz muito fruto" (Cf Jo, 12,24).

Como capelão de um grande hospital tenho tido a oportunidade de acompanhar pacientes que ficaram cegas, mutiladas, paraplégicas, tetraplégicas ou que tiveram os mais diferentes tipos de perdas físicas e emocionais. Nestas circunstâncias, é impressionante observar a capacidade de adaptação que essas pessoas e o próprio corpo demonstram.

No entanto, na convivência comunitária, profissional e principalmente na vida conjugal, existem os outros tipos de mortes que muitas vezes passam desapercebidos. Estou me referindo a morte da ética, da justiça, dos gestos humanitários, do amor, do perdão, do desprendimento, da solidariedade, do respeito, da confiança, do afeto, da tolerância, da compreensão, do diálogo, da fé, da alegria, da amizade, da esperança, do gosto pela vida que afetam, diariamente, quase todos nós.

Essas "mortes" que mereceriam uma discussão individualizada, embora não necessariamente nos separam fisicamente das pessoas, provocam verdadeiros traumas e danos interiores, fruto das somatizações, e também males externos que, de uma maneira ou de outra afeta não somente a nós mas também aqueles que convivem conosco.

\section{A PREOCUPAÇÃO ATUAL}

Atualmente e por uma questão lógica, fala-se muito na importância de morrer com dignidade. Para isso, segundo os especialistas em ética, moral e bioética, além do cuidado que é o ponto fundamental, pois segundo Cecília Saunders 5 "o pior sofrimento é aquele que não é cuidado", sugerem que deve se entender bem o significado da eutanásia, dizer não a distanásia que é sinônimo de morte sofrida, e apelar para a ortotanásia que pode ser entendida como morte digna.

Ao usarmos toda tecnologia que está à disposição da medicina podemos, ainda que contra nossa vontade, prolongar, não somente a vida mas também o sofrimento da pessoa. Daí toda a preocupação de não se estender, por tempo indeterminado, o processo do morrer.

Essa inquietação é muito pertinente e necessária. Porém, para o bem de todos e não somente daquele que está morrendo fisicamente, será que estes outros tipos de mortes, acima citados, não merecem, uma reflexão, toda especial?

Portanto, a mesma dedicação e empenho que colocamos no atendimento daqueles que sofrem com a aproximação da morte física deveríamos colocar também a serviço dos que sofreram outros tipos de morte.

\section{A MORTE É PROBLEMA OU SOLUÇÃO?}

Esta pergunta feita há alguns tempos atrás poderia causar certo espanto, pois falar de morte significa falar em perda. E ninguém gosta de perder. Principalmente em se tratando de uma pessoa querida. Mas hoje, com a revolução provocada pela técnica, parece não ser tão absurdo vê-la como solução.

É claro que a perda do chefe de família que dele dependia todo sustento da casa. A morte da mãe, que além de cuidar da casa, precisava trabalhar fora para ajudar nas despesas. A interrupção de uma vida que despontava como uma grande promessa. A morte súbita de um jovem que, na flor da idade, deixa seus pais numa profunda tristeza pois ele era não somente esperança do futuro, mas orgulho dos pais. A mulher que, na ânsia de ser mãe, e tanto esperava o filho, acaba morrendo no parto. Ou então o filho tão desejado que já nasceu sem vida.

É a sensação de fracasso por parte dos profissionais que foram treinados e acostumados a salvar vidas, e vêem que, muitas vezes, ela escapa de suas mãos. É a difícil tarefa do capelão, psicólogo assistente social, médico ou enfermeiro de comunicar aos fa- 
miliares que seu ente querido não resistiu e faleceu. É o problema dos medicamentos que custam tanto e tanto prometem, e na verdade acabam não dando resultados. É o transplante que paciente, familiares e profissionais tanto aguardam e que acaba no centro cirúrgico, ou alguns dias depois. Nestes momentos, somos incapazes de ver a morte como solução.

No entanto não podemos esquecer que a morte, que tanto tememos, que nos aborrece e às vezes nos deixa revoltados até contra o Criador, outra vezes possibilita um agradecimento. Quantas vezes já não agradecemos a Deus a morte de alguém? Embora prefiro acreditar que seja por compaixão e não por outras razões.
Outro fator que nos faz refletir e vermos a morte como solução são casos em que pacientes estão necessitando de um leito de UTI (Unidade de Terapia Intensiva). Poderíamos nomear os famosos casos que chamaríamos de "eutanásia social", onde é preciso escolher, entre dois pacientes, qual deverá ir para a UTI. De repente, um morre! É difícil fazer essa afirmação, mas é um problema a menos para resolver...

Portanto, entendendo que a morte não é apenas um fato biológico, haja vista que a morte de um ser humano é também a morte de um ser social, começo acreditar que, realmente, a morte pode ser a solução para os problemas do que morreu e também daqueles que continuam vivos.

Baldessin A. (Padre). A well-equipped passing away. Medicina (Ribeirão Preto) 2005; 38(1): 55-59.

Abstract: Death, mainly in the occidental culture, was always faced by a strong reaction. This reality can be confirmed everyday, where we can see that children are more and more separated from the death intimacy. To escape from that reality, medical science, with the help of the high technology, searchs for options to remove the "ghost"of death.

The proposal of this article is to consider the use of technology, which at the same time that extends life, brings also suffering to the patient, family, professionals, and to all those who are responsible for the costs of the hospitalization. The author calls the attention to the following: While one expends a lot of time and money trying to avoid physical death, little or almost nothing is done to avoid other types of death that frequently are worse than the physical death.

Keywords: Death. Orthotanasia.

\section{REFERÊNCIAS BIBLIOGRÁFICAS}

1 - Callahan D. The tyranny of survival. 2th ed. New York: Rowman \& Littlefield; 1985.

2 - Moraes J. Viciados em remédios. Revista Superinteressante fev. 2003; ano VIII (326):42-5
3 - Dobzhansky T. Episcopato Tedesco. La cura per i morti. II Regno Documenti 1995 (40):135-55.

4 -Kushner H. Quando tudo não é o bastante. São Paulo:Nobel; 1983.

5 - Saunders C. Caring the end nursing. London: Mirror; 1980. 